\title{
Binding Sites for Bacterial Flagella at the Surface of the Soil Amoeba Acanthamoeba
}

\author{
By T. M. PRESTON* AND C. A. KING \\ Department of Zoology, University College London, Gower Street, London WC1E 6BT, UK
}

(Received 22 September 1983; revised 7 December 1983)

\begin{abstract}
Acanthamoeba castellanii (CCAP 1534/3) was found to bind avidly the common soil bacterium Pseudomonas fluorescens. This adhesion was mediated not by pili nor by the general bacterial surface but by the polar flagella. Because of the nature of the flagellar rotary motor, the cell bodies of the attached bacteria could be seen rotating clearly. While initially bacterial binding occurred uniformly over the cell membrane of Acanthamoeba, the bacteria were soon swept posteriorly to form a cap and either endocytosed or sloughed off, still agglutinated by their flagella. Such capped amoebae would not bind Pseudomonas if challenged immediately, indicating a depletion of flagella-binding sites. The bacteria could not bind to amoebae pretreated with concanavalin A (Con A) even after the lectin had been capped to the uroid. However, capping of flagella-binding sites did not co-cap all the Con A-binding sites on the surface of the amoeba. The flagella-binding sites were not affected by pre-treatment with Pronase ( $1 \mathrm{mg} \mathrm{ml}^{-1}$ ) or anti-Acanthamoeba surface antibody. Proteus mirabilis also bound avidly by its flagella to Acanthamoeba and, furthermore, competition experiments suggested that Proteus and Pseudomonas adhere to a common surface site on the amoeba. The presence of sites on the cell membrane of $\boldsymbol{A}$. castellanii that are specific for flagellin would enhance strongly the adsorption of motile bacteria prior to endocytosis. This would represent an excellent feeding strategy for a soil-dwelling phagotroph.
\end{abstract}

\section{INTRODUCTION}

It is widely appreciated that in metazoan organisms cell surfaces play a key role in molecular recognition phenomena that occur, for example, during embryogenesis. Amoeboid Protozoa, with rare exceptions (Dictyostelium, for example), do not indulge in social behaviour and so any surface recognition ability they might have would be expected to be directed towards their feeding behaviour. Although some amoebae may be expressly carnivorous (Amoeba, Chaos) and others herbivorous (Pelomyxa) nothing is known of the mechanism of this selectivity. In certain circumstances the control of food preferences may have considerable repercussions on the stability of a host-parasite relationship, e.g. in previously asymptomatic human infections with Entamoeba histolytica a switch in the diet of the trophozoites from gut flora to host cells precipitates the onset of amoebic dystentery.

Ray (1951) described the ability of Hartmannella (= Acanthamoeba) to accumulate large numbers of motile bacteria at its periphery. These agglutinated bacteria were endocytosed after being swept backwards into what she termed a 'cap'. The wider significance of this finding was not appreciated, and it is ironic that it was 20 years later that what is generally considered to be the first description of 'capping' was made. This was an account of an analogous process, namely the redistribution of externally cross-linked cell-surface receptors on mammalian lymphocytes (Taylor et al., 1971).

We have investigated the nature of this binding property displayed by Acanthamoeba not only for its intrinsic interest but also because there is currently much discussion about the adherence of bacteria to eukaryotic cells (see Beachey, 1980 for a recent review). In many instances the

Abbreviations: Con A, concanavalin A; FITC, fluorescein isothiocyanate. 
adhesiveness of bacteria is conferred by the presence of filamentous, proteinaceous appendages termed pili. There is persuasive evidence that these pili can recognize particular chemical groups on the surface, for example, of epithelial cells and thus, through a stereospecific interaction, secure adherence to the eukaryote as a first step in colonization. It is known that the pili of Escherichia coli display lectin-like behaviour towards D-mannose (Ofek et al., 1977). On the other hand, there is little information concerning bacterial adhesion to biological surfaces by means of their flagella alone, although some strains of $E$. coli carrying mutations in the structural gene for flagellin ( $\mathrm{hag}$ ) produce flagella which show an increased stickiness to glass (Icho \& Iino, 1978).

In this paper we show that several species of Acanthamoeba have the capacity to bind motile bacteria to their surface by means of the bacterial flagella.

\section{METHODS}

Protozoa. Samples of the following stocks of amoebae were obtained from the Culture Centre of Algae and Protozoa, Cambridge, UK: Acanthamoeba astronyxis (1534/1), A. castellanii (1534/3) and (1501/1), Dictyostelium mucoroides (1515/1), Naegleria gruberi (1518/1c), Paratetramitus jugosus (1588/3f) and Tetramitus rostratus (1581/1). Acanthamoeba spp. were grown axenically as monolayers in tissue culture flasks at $25^{\circ} \mathrm{C}$ in a liquid medium (Korn, 1963). Cultures were harvested in the exponential growth phase. First unattached cells were removed by decanting the growth medium. Adhesive cells were then removed into $50 \mathrm{mM}-\mathrm{NaCl}$ by vigorous shaking of the flask and then concentrated by gentle centrifugation. After a repeat of this cycle, the amoebae were resuspended in $50 \mathrm{mM}-\mathrm{NaCl}$ at $10^{7}$ cells $\mathrm{ml}^{-1}$. The other amoebae were maintained at $25^{\circ} \mathrm{C}$ in monoxenic culture with Escherichia coli on agar plates and harvested free from bacteria as described previously (Preston \& King, 1978).

Bacteria. Pseuodomonas fiuorescens RIII ${ }^{6}$ was isolated from soil cores taken from the grounds of King's College field station, Rogate, W. Sussex, UK. Small crumbs of soil were incubated in $10 \mathrm{ml}$ sodium benzoate medium $\left(5 \mathrm{~g} \mathrm{NaCl}, 0.2 \mathrm{~g} \mathrm{MgSO}_{4}, 1 \mathrm{~g}\left(\mathrm{NH}_{4}\right)_{2} \mathrm{HPO}_{4}\right.$ and $2 \mathrm{~g}$ sodium benzoate $\left.1^{-1}, \mathrm{pH} \mathrm{6.8}\right)$ at $25^{\circ} \mathrm{C}$ for several days. Samples from any turbid supernatants were streaked onto King-Ward-Raney agar plates $(20 \mathrm{~g}$ peptone, $1.5 \mathrm{~g}$ $\mathrm{K}_{2} \mathrm{HPO}_{4}, 1.5 \mathrm{~g} \mathrm{MgSO}_{4} .7 \mathrm{H}_{2} \mathrm{O}, 10 \mathrm{~g}$ sodium succinate and $\left.15 \mathrm{~g}_{\text {agar }}{ }^{-1}\right)$. Ps. fiuorescens colonies were identified by their yellow coloration and UV-excited fluorescence. Clones prepared from such colonies were subsequently maintained on nutrient agar plates. Bacteria used were from plates less than $24 \mathrm{~h}$ old to measure maximum motility.

Stocks of Proteus mirabilis and Rhodospirillum rubrum were generously provided by Dr D. G. Smith (Department of Botany and Microbiology, University College, London, UK). Pr. mirabilis swarmers were isolated by transferring cells from an established colony to the centre of a fresh nutrient agar plate with a wire loop. The swarmers, which by $24 \mathrm{~h}$ had migrated out radially from the central colony to a distance of 3-4 cm, could be harvested free of short forms.

Lectin and antisera. Native and fluorescein (FITC)-labelled concanavalin A (Con A) was obtained from Miles Laboratories, Stoke Poges, Slough, UK, and used at a final concentration of $100 \mu \mathrm{g} \mathrm{ml}^{-1}$ with $5 \times 10^{6}$ cells.

Antisera to $A$. castellanii $1534 / 3$ were prepared by intramuscular injection of suspensions of formalin-treated amoebae in Freund's complete adjuvant into rabbits with a booster dose given three weeks later. The antiserum from one rabbit (T101) had activity directed against the surface of $A$. castellanii $1534 / 3$, as judged by immunofluorescence and by immunodiffusion tests against both water soluble and Triton X-100 extracts of unfixed amoebae. This crude antiserum was subjected to ammonium sulphate fractionation to yield the $\gamma$-globulin component. This fraction was used as the source of anti-Acanthamoeba antibody in the experiments reported below.

Tetramethyl rhodamine isothiocyanate-labelled rabbit antiserum to Con A was obtained from Nordic Immunological Laboratories, Maidenhead, UK. IgG fractions of goat antiserum to rabbit IgG, labelled with FITC, were obtained from Miles Laboratories.

Electron microscopy. Amoebae suspended in $50 \mathrm{mM}-\mathrm{NaCl}$ were allowed to settle for $20 \mathrm{~min}$ on detergent-cleaned coverslips in a humid chamber. Small amounts of a suspension of Ps. fiuorescens in $50 \mathrm{mM}-\mathrm{NaCl}$ freshly harvested from nutrient agar plates were added to these amoebae; this was taken to be time zero. The first group of coverslips was immersed in a dialdehyde fixative at room temperature after $3 \mathrm{~min}$ and then the second after $20 \mathrm{~min}$. The dialdehyde fixative had the following composition: $1 \%(w / v)$ glutaraldehyde, $2 \%(w / v)$ freshly prepared formaldehyde, and $2 \mathrm{mM}-\mathrm{CaCl}_{2}$ in $10 \mathrm{mM}$-HEPES buffer at $\mathrm{pH} 7 \cdot 3$. After $15 \mathrm{~min}$ the coverslips in fixative were transferred to $3{ }^{\circ} \mathrm{C}$ for a further $2 \mathrm{~h}$, then washed thoroughly in ice cold $10 \mathrm{mM}$-HEPES buffer at $\mathrm{pH} 7.3$ and postfixed in $1 \%(\mathrm{w} / \mathrm{v}) \mathrm{OsO}_{4}$ in the same buffer at $3{ }^{\circ} \mathrm{C}$ for $1 \mathrm{~h}$.

Samples for scanning electron microscopy were then dehydrated directly through a graded series of ethanol/water mixtures before critical point drying. These specimens were coated with carbon then gold before 
examination in a Cambridge S4-10 microscope at 10 or $30 \mathrm{kV}$. Ilford FP4 emulsion was used for photographic records.

Following postfixation in $\mathrm{OsO}_{4}$, samples to be processed for transmission electron microscopy were immersed in $0.5 \%(\mathrm{w} / \mathrm{v})$ aqueous uranyl acetate for $30 \mathrm{~min}$ before dehydration through ethanol/water mixtures. After three changes in absolute ethanol the specimens were transferred via a $1: 1$ acetone/Araldite mixture to complete Araldite resin and then left overnight at $25^{\circ} \mathrm{C}$. The next day coverslips were transferred to fresh resin for embedding. Coverslips were removed from the polymerized blocks after these had been softened by plunging into boiling water. Thin sections of chosen groups of cells were cut parallel to the original planar glass substrate on a diamond knife mounted on a Huxley ultramicrotome. Sections collected on uncoated copper grids were stained in lead citrate and then examined in an AEI EM6B microscope operated at an accelerating voltage of $60 \mathrm{kV}$ with an objective aperture of $50 \mu \mathrm{m}$. Images were recorded on Kodak EM4489 emulsion.

Light microscopy. Phase-contrast and fluorescence microscopy was done on a Leitz Orthoplan stand fitted routinely with Zeiss objective lenses. Photographic records were made on Kodak Tri-X or Ektachrome 400 emulsion. Recordings of cell behaviour were made by means of a videocamera connected to an inverted Zeiss Ultraphot stand and linked to a videorecorder and TV monitor (Preston \& King, 1978).

Surface labelling of cells. The following procedure was adopted as a standard for labelling Acanthamoeba with antibody or lectin. Cell suspension $\left(0.5 \mathrm{ml}, 10^{7}\right.$ cells $\left.\mathrm{ml}^{-1}\right)$ in $50 \mathrm{mM}-\mathrm{NaCl}$ was pipetted into a plastic centrifuge tube held in an ice bucket. Antibody or lectin was then added together with enough saline to bring the final volume to $1 \mathrm{ml}$. After $30 \mathrm{~min}$ incubation the cells were gently pelleted and washed twice with ice cold saline and finally resuspended in $0.5 \mathrm{ml}$ of this solution. Where second layer labelling was required these resuspended cells were incubated on ice for a further $30 \mathrm{~min}$ with the requisite ligand, then washed thoroughly before resuspension and microscopic examination. Tests by fluorescence microscopy for non-specific absorption of rabbit or goat $\gamma$ globulin at the surface of Acanthamoeba proved negative.

The availability of Con A-binding sites at the cell surface of Acanthamoeba following adsorption of bacteria was tested as follows. Cells settled in plastic dishes were challenged with a suspension of $P$ s. fluorescens in $50 \mathrm{mM}-\mathrm{NaCl}$ and then fixed some 20 min later with $2 \%(w / v)$ formaldehyde. After extensive washing in $1 \%(w / v)$ glycine in $50 \mathrm{mM}-\mathrm{NaCl}$, to block any reactive aldehyde groups introduced by the fixative, these substrate-attached amoebae were treated with FITC-Con A for $30 \mathrm{~min}$, washed thoroughly with $50 \mathrm{mM}-\mathrm{NaCl}$ and then examined with a X40 Zeiss phase-contrast water-immersion objective lens.

\section{RESULTS}

\section{Light microscopy}

When a suspension of freshly harvested Ps. fluorescens was added to $A$. castellanii $1534 / 3$ cells that had been allowed to settle for $15 \mathrm{~min}$ on a clean coverslip in $50 \mathrm{~mm}-\mathrm{NaCl}$, the actively swimming bacteria stuck to the amoebae on colliding with them. Within a few minutes these amoebae were entirely covered with bacteria. On close inspection the bacteria were seen to be attached solely by their polar flagella and did not appear to be stuck to each other. Since their flagella were tethered to the surface of the amoebae, the bacterial cell bodies rotated producing a jostling monolayer around each amoeba. Although they remained attached to the substratum, many amoebae had rounded up from their previous extended locomotory shape at this stage. Subsequently, the uniform bacterial layer became redistributed as each protozoon recommenced locomotion. The anterior (leading) edge of an amoeba was cleared of bacteria first, and the bound bacteria became increasingly concentrated in the posterior (uroid) region as a welldefined cap. Such capped amoebae when challenged with fresh bacteria were found to bind few (if any) of the added bacteria. By this time it was possible to see within these moving amoebae phagosomes containing varying numbers of Ps. fluorescens. However, not all the bacterial aggregates were endocytosed and some were shed from the uroid into the medium.

If the fixed Acanthamoeba were substituted for live cells bacterial binding still took place to form a uniform layer around each protozoon, but neither redistribution into a cap nor endocytosis took place.

This pattern of behaviour with Ps. fluorescens was not confined to $A$. castellanii $1534 / 3$ but was demonstrated by each of the Acanthamoeba stocks used. On the other hand, there was no evidence of flagellar binding of this bacterium to the surface of other common soil amoebae such as Naegleria, Tetramitus, Paratetramitus and Dictyostelium.

The surface agglutination phenomenon displayed by Acanthamoeba was not specific for Pseudomonas alone since actively motile forms of the unrelated bacteria Proteus mirabilis and 

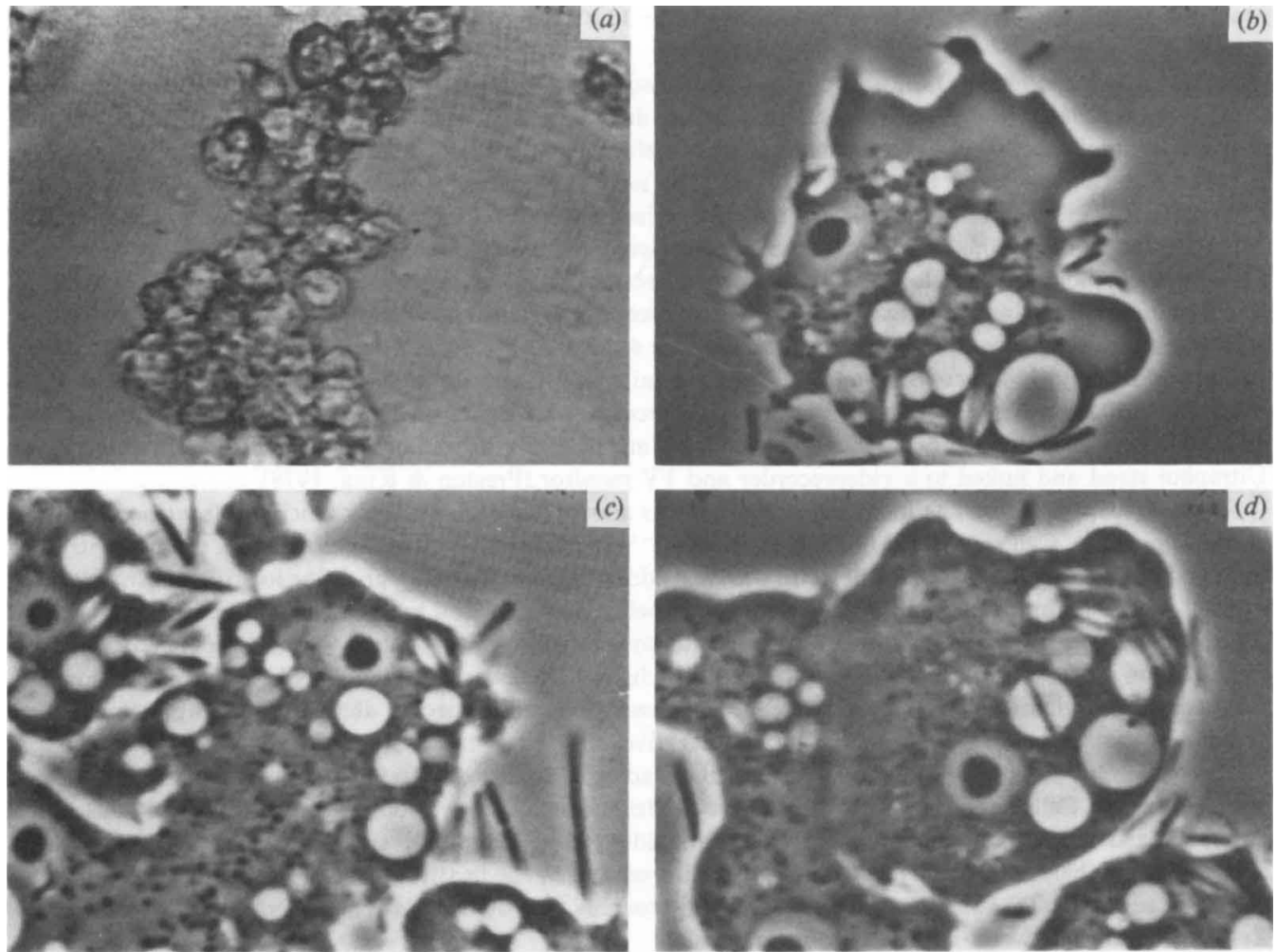

Fig. 1. (a) Bright field micrograph of a suspension of Acanthamoeba cells in $50 \mathrm{mM}-\mathrm{NaCl}$ agglutinated by the addition of Rhodospirillum rubrum. No significant agglutination occurred in controls without $R$. rubrum. Magnification approx. $\times 350$. $(b-d)$ Phase-contrast micrographs of stages in the process of polar binding of $R$. rubrum to the surface of Acanthamoeba and the subsequent endocytosis of the prokaryotes. Phagosomes containing single bacteria are particularly clear in $(d)$. Magnification approx. $\times 1070$.
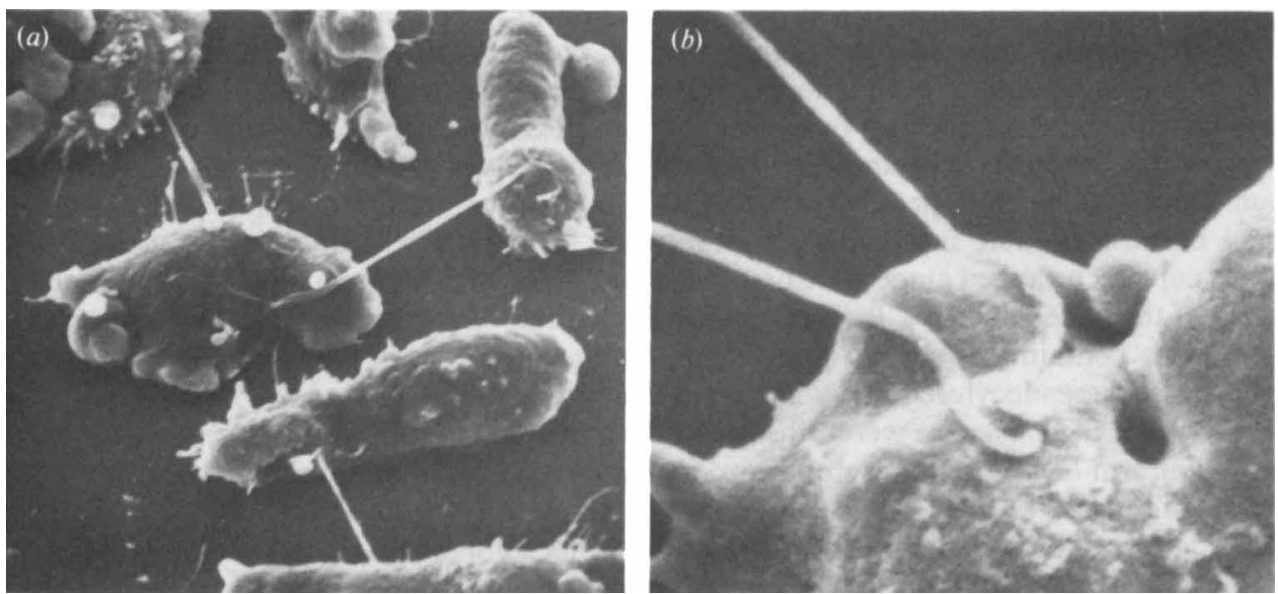

Fig. 2. (a) Scanning electron micrograph demonstrating the ease with which the peritrichous swarm cells of Proteus mirabilis can cross-link locomoting amoebae. Magnification approx. $\times 1800$. $(b)$ Scanning electron micrograph showing two Pr. mirabilis swarm cells tightly bound to, and following the surface contours of, an individual Acanthamoeba. Magnification approx. $\times 7560$. 
Rhodospirillum rubrum were captured with equal facility and subsequently capped. Unlike Pseudomonas, Rhodospirillum bears flagella at both poles, and it was therefore able to cause agglutination of amoebae when added to Acanthamoeba in suspension (Fig. 1a). Proteus, in contrast to Pseudomonas and Rhodospirillum, is peritrichous and was therefore not restricted simply to polar attachments on collision with Acanthamoeba. Indeed any region of the Proteus cell was able to attach to the surface of the amoeba (see Fig. $2 b$ ). In some cases a single bacterium was attached at both ends to an individual amoeba resulting in the bacterium being held in an arc-like position. In other cases it was found that one bacterial swarm cell could crosslink two amoebae (see Fig. 2a).

Whereas Acanthamoeba had no difficulty in endocytosing Pseudomonas it could engulf only the smallest representatives of populations of Rhodospirillum (Fig. $1 b-d$ ) and Proteus.

\section{Electron microscopy}

The general morphological features of the bacterial interaction with Acanthamoeba inferred from phase-contrast microscopy were borne out by scanning and transmission electron microscopy. Scanning electron microscopy of Acanthamoeba fixed $3 \mathrm{~min}$ after exposure to $P s$. fluorescens revealed the initial high density of bacterial packing at the surface of the amoeba and confirmed the lack of anything but polar adhesion of the prokaryote cells (Fig. $3 a$ ). In preparations of Acanthamoeba fixed 20 min after exposure to bacteria, the majority of amoeba had already resumed locomotion and had redistributed bound pseudomonads into a posterior cap (Fig. $3 b$ ). There was no evidence for additional bacteria being bound anteriorly on these cells.

Despite the strength of the bacterial adhesion to Acanthamoeba there was always a large gap between the cell body of Pseudomonas and the plasmalemma of the protozoon (Fig. $4 a$ ). Only bacterial flagella were to be seen making direct contact with the cell surface of Acanthamoeba (Fig. 4b).

\section{Experimental treatments aimed at blocking bacterial binding to A. castellanii 1534/3 amoebae}

Use of anti-Acanthamoeba antibody. Amoebae treated with T101 (anti-Acanthamoeba) antibody followed by FITC-labelled goat anti-rabbit IgG demonstrated strong surface fluorescence. This fluorescence was originally uniform, becoming redistributed into patches which were then capped as the cells recommenced locomotion. When amoebae were labelled with this anti-Acanthamoeba antibody and then challenged with Ps. fluorescens, the bacteria attached by their flagella to the surface of the amoeba on collision. Bacteria were seen to bind on both patched and cleared areas of Acanthamoeba surface membrane.

Use of the lectin Con A. Amoebae exposed in the cold to FITC-Con A were uniformly coated by this lectin. If these cells were immediately challenged with suspensions of Ps. fluorescens the bacteria did not stick to the amoebae in spite of making numerous collisions. Even when the bacterial challenge was delayed until after the bound lectin had been capped with a second layer antibody directed against Con $\mathbf{A}$, flagellar binding was still inhibited. When amoebae labelled with FITC-Con A were incubated in the corresponding hapten (methyl $\alpha$-D-mannopyranoside) at $50 \mathrm{~mm}$ final concentration the fluorescent lectin was rapidly lost. We had previously established that at this concentration the sugar had no effect on bacterial binding to untreated Acanthamoeba. Therefore, immediately after amoebae had been surface-labelled with FITCCon A they were challenged with Ps. fluorescens in the presence of competing sugar. Only those amoebae which had lost their fluorescence were able to bind the bacteria in an optimal manner.

A reciprocal experiment was carried out in which amoebae were challenged first with $P s$. fluorescens and then tested to see if they could still bind FITC-Con A. Even though they had bound and, in many cases, successfully capped bacteria, the amoebae were still able to take up FITC-Con A uniformly over the surface.

In order to check whether the peripheral binding sites for bacterial flagella on $A$. castellanii $1534 / 3$ contained exposed protein, amoebae were preincubated in Pronase before challenge with either Ps. fluorescens or FITC-Con A. Such proteolytic treatment did not remove the ability to bind bacteria or lectin. 


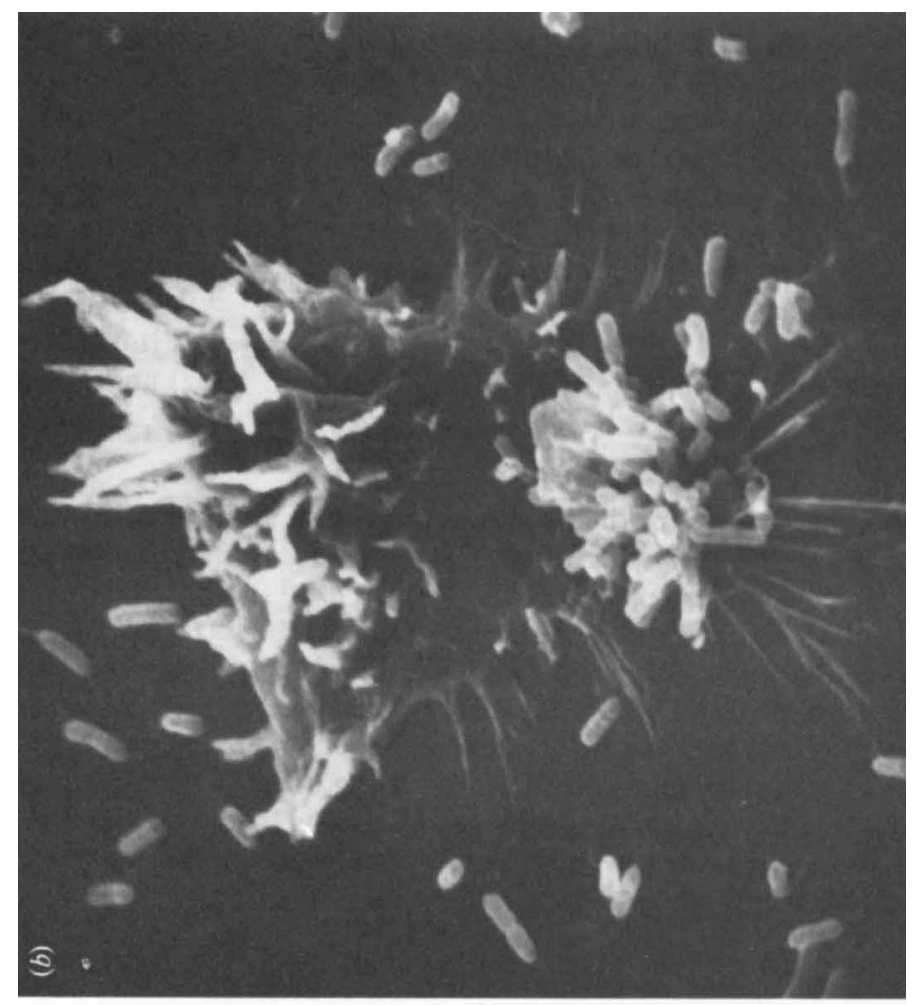

홇올

要

过 约

西.

نं

돌

政

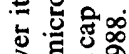

ว

당 욜 $x$

당

象

무의

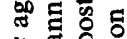

ริ

现㑒

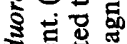

要茫

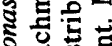

㢦吉

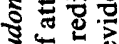

을

Q.

号宗西

政

号

西品

跑票

3 \&

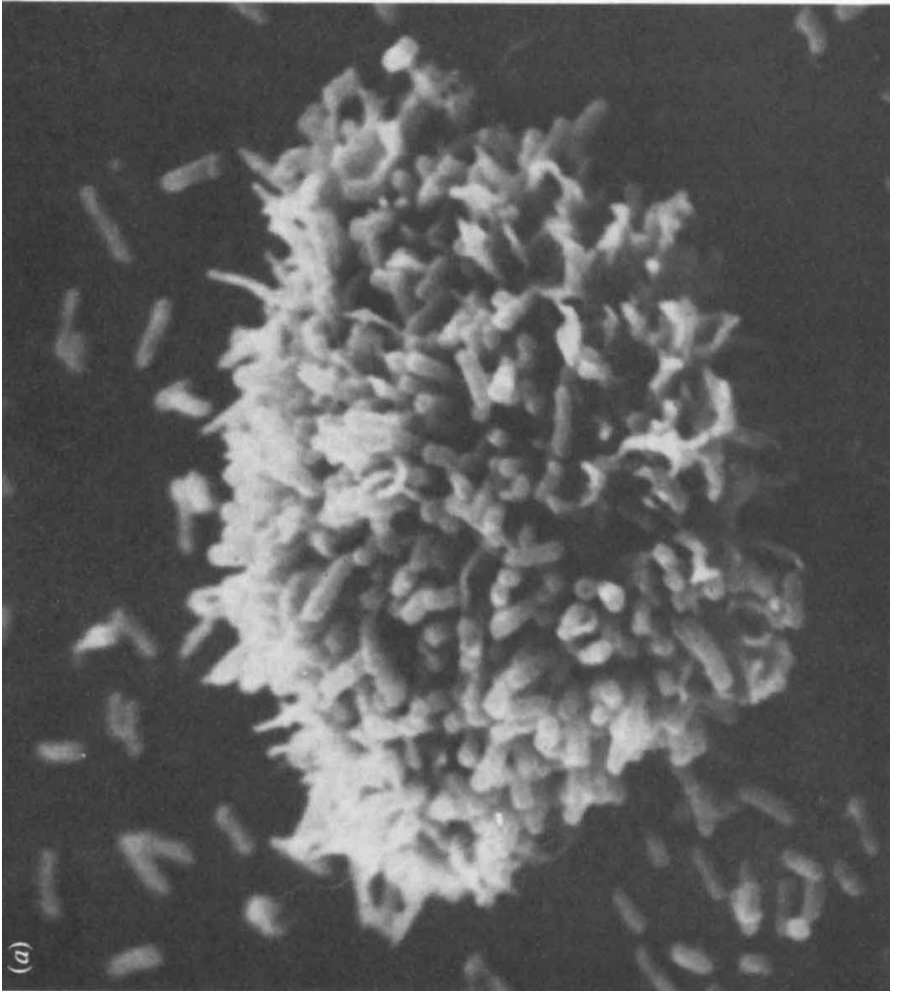

응 可

웡

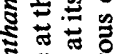

5

$\checkmark$.

궁

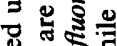
要的专 항. 을 웡 $\pi$ 元 드요

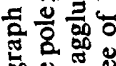
究 을

ह

ธี 잉 는음 on 혈 용 苍 可院 लंख

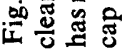



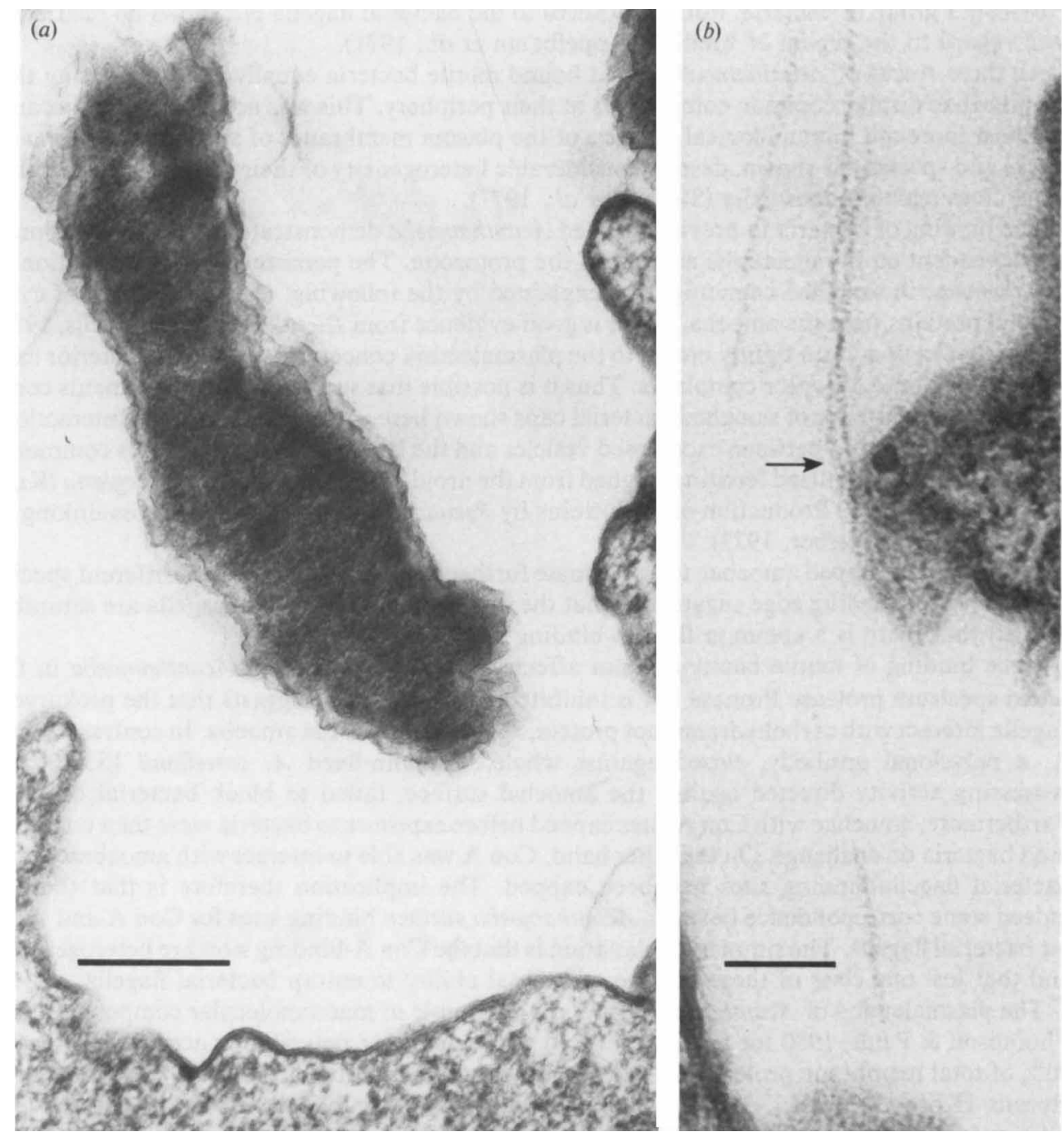

Fig. 4. (a) Transmission electron micrograph of a thin section showing the considerable gap between the cell body of a trapped bacterium (Ps. fluorescens) and the surface of an Acanthamoeba. Bar, 0.25 $\mathrm{mm}$. (b) Micrograph showing a typical arrangement of flagellar filaments of bacteria attached to the surface membrane of Acanthamoeba (arrowed). Bar, $0 \cdot 1 \mu \mathrm{m}$.

\section{DISCUSSION}

The experiments reported here confirm the original report (Ray, 1951) of surface agglutination and subsequent redistribution of motile bacteria by Hartmanella (= Acanthamoeba), extend our understanding of the bacteria-amoeba interaction, and suggest the presence of surface membrane sites on amoebae which are specific for the binding of bacterial flagella. Pseudomonas fluorescens attaches to Acanthamoeba only by one pole, and then exhibits active rotation of its body in the same manner as $E$. coli tethered to a glass slide coated with specific antibody to flagellin (Silverman \& Simon, 1974). This suggests strongly that adhesion is mediated via the prokaryote flagellum. Our electron microscope observations are in accord with this interpretation and also indicate that adhesion may not be confined to the flagellar tip. It should be noted that the phage $\phi \chi_{7}$, which attacks many motile strains of the Proteus- 
Providence group of bacteria, initially adsorbs to the bacterial flagella but shows no restriction with regard to the region of binding (Appelbaum et al., 1971).

All three stocks of Acanthamoeba tested bound motile bacteria equally well, suggesting that the amoebae display common components at their periphery. This was not unexpected because the most thorough immunological analysis of the plasma membranes of several Acanthamoeba stocks and species has shown, despite considerable heterogeneity of their surface antigens, that some cross-reaction does exist (Stevens et al., 1977).

The binding of bacteria to previously fixed Acanthamoeba demonstrates that agglutination is not dependent on the metabolic activity of the protozoon. The persistence of agglutination of Pseudomonas in sloughed caps might be explained by the following. (a) Involvement of cytoskeletal proteins from the amoeba. There is good evidence from Dictyostelium (Condeelis, 1979) that cortical actomyosin tightly bound to the plasmalemma concentrates into the posterior caps induced by Con A-receptor complexes. Thus it is possible that such cytoskeletal elements could explain the persistence of sloughed bacterial caps shown here in Acanthamoeba. (b) Interactions occurring at the uroid between exocytosed vesicles and the bacteria. This situation is commonly found in caps of cationized ferritin sloughed from the uroid of the limax amoeba Naegleria (King \& Preston, 1977). (c) Production of agglutinins by Pseudomonas leading to the cross-linking of bacteria (Gilboa-Garber, 1972).

The failure of capped amoebae to agglutinate further bacteria of the same or different species at their cleared leading edge suggests (i) that the surface binding sites for flagella are saturable and (ii) that there is a common flagella-binding site for all bacteria.

Since binding of motile bacteria is not affected by preincubation of Acanthamoeba in the broad spectrum protease Pronase but is inhibited by Con A, this suggests that the prokaryote flagella interact with carbohydrates, not protein, at the surface of the amoeba. In contrast to Con A, a polyclonal antibody, raised against whole, formalin-fixed $A$. castellanii $1534 / 3$ and possessing activity directed against the amoebal surface, failed to block bacterial binding. Furthermore, amoebae with Con A sites capped before exposure to bacteria were then unable to bind bacteria on challenge. On the other hand, Con $\mathrm{A}$ was able to interact with amoebae whose bacterial flagella-binding sites had been capped. The implication therefore is that there is indeed some correspondence between Acanthamoeba surface binding sites for Con A and those for bacterial flagella. The simplest explanation is that the Con A-binding sites are heterogeneous and that just one class of these has the additional ability to entrap bacterial flagella.

The plasmalemma of Acanthamoeba is relatively simple in macromolecular composition (see Thompson \& Pauls, 1980 for a recent review) with one major polypeptide accounting for 40 $50 \%$ of total membrane protein and two carbohydrate-containing molecules - lipophosphonoglycans (Korn \& Wright, 1973). These two inositol-containing glycosphingolipids have a different sugar composition but are otherwise similar and together constitute about one-third of the plasmalemma mass (Dearborn et al., 1976). There are no glycoproteins in the plasmalemma. Consequently the acidic carbohydrates visualized at the surface of intact cells (and on both faces of isolated plasmalemmas) by electron microscope cytochemistry (Bowers \& Korn, 1974) suggest that some part of the lipophosphonoglycan molecules is exposed to the exterior.

Bacterial flagellar filaments are considered to be composed entirely of a single protein flagellin (Smith, 1982). As yet there is no evidence of accessory carbohydrate along the filament and we were unable to induce flagellar agglutination of Pseudomonas with Con A. From this it seems likely that adsorption of bacteria to the surface of Acanthamoeba is due to an interaction between the protein flagellin and some carbohydrate residues of amoebal lipophosphonoglycan. Up to now there has been no clear function ascribed to these lipophosphonoglycans in spite of their abundance in the plasmalemma. The implication of at least some of them in food capture by stereospecific interaction with a prey macromolecule would bear out an earlier suggestion (Dearborn \& Korn, 1974) that these membrane components might serve functions similar to those played by glycoproteins and glycolipids at metazoan cell surfaces. There is indeed evidence that the cell surface carbohydrates of eukaryotes play a central role in recognition phenomena (Berger et al., 1982).

Since the bacterial flagellum is a linear polymer of flagellin, one filament could readily 
interact with several independent binding sites on the Acanthamoeba cell. In so doing the prokaryote would effectively cross-link these receptors and fulfil the preliminary conditions required for patching and endocytosis either immediately or subsequently at the uroid following cap formation.

It is of interest that other common naked amoebae, Naegleria, Tetramitus, Dictyostelium and Paratetramitus, often occupy the same soil ecosystem as Acanthamoeba. Although these organisms do not present an agglutinating surface to bacterial flagella, they nonetheless feed avidly on these microbes. The adhesive 'fly paper' method of capturing food in an aqueous environment is by its very nature non-selective. Ps. fluorescens, while providing an excellent model for studying flagellar adhesion to Acanthamoeba, will not support, unlike $E$. coli, the growth of $A$. castellanii $1534 / 3$ on agar plates. Acanthamoeba castellanii has been isolated from soil and freshwater samples as a predator of both unicellular and filamentous cyanobacteria (Wright et al., 1981). This clearly indicates that in vivo this protozoon does not feed exclusively on flagellated prokaryotes and that it may deploy a repertoire of surface recognition properties for use in feeding.

Although many classical studies on endocytosis have been carried out on the phagocytosis of latex beads by Acanthamoeba (Weismann \& Korn, 1967), little work has been done on the possible specificity in the endocytotic reactions. However, Brown et al. (1975) proposed that Acanthamoeba might bind potential food organisms by means of an undefined surface lectin which could recognize specific carbohydrate residues in their prey.

The range of surface binding properties of Acanthamoeba and their expression as a function of environmental factors warrants further study, for some species are able to become opportunistic pathogens in man causing meningoencephalitis (A. culbertsoni; Culbertson, 1971) and keratitis (A. polyphaga; Visvesvara et al., 1975).

We wish to thank L. G. Cooper for excellent technical assistance. SEM services were provided by the University of London Board of Studies in Zoology. This work was supported by a SERC grant to T. M. P.

\section{REFERENCES}

Appelbaum, P. C., Hugo, N. \& Coetzee, J. N. (1971). A flagellar phage for the Proteus-Providence group. Journal of General Virology 13, 153-162.

BEACHEY, E. H. (Ed.) (1980). Bacterial Adherence. Receptors and Recognition, series B, vol. 6. London: Chapman \& Hall.

Berger, E. G., Buddecke, E., Kamerling, J. P., Kobata, A., Paulson, J.-C. \& Vliegenhart, J. F. G. (1982). Structure, biosynthesis and functions of glycoprotein glycans. Experientia 38, 1129-1162.

BOWERS, B. \& KORN, E. D. (1974). Localization of lipophosphonoglycan on both sides of the Acanthamoeba plasma membrane. Journal of Cell Biology 62, 533-540.

Brown, R. C., Bass, H. \& Coombs, J. P. (1975). Carbohydrate binding proteins involved in phagocytosis by Acanthamoeba. Nature, London 254, 434-435.

CONDEELIS, J. (1979). Isolation of concanavalin A caps during various stages of formation and their association with actin and myosin. Journal of Cell Biology 80, 751-758.

Culbertson, C. G. (1971). The pathogenicity of soil amebas. Annual Review of Microbiology 25, 231-254.

DeARBorn, D. G. \& Korn, E. D. (1974). Lipophosphonoglycan of the plasma membrane of Acanthamoeba castellanii. Journal of Biological Chemistry 249, 3342-3346.

Dearborn, D. G., SMith, S. \& KorN, E. D. (1976). Lipophosphonoglycan of the plasma membrane of
Acanthamoeba castellani: inositol and phytosphingosine content and general structural features. Journal of Biological Chemistry 251, 2976-2982.

GILBOA-GARBER, N. (1972). Inhibition of broad spectrum haemagglutinin from Pseudomonas aeruginosa by D-galactose and its derivatives. FEBS Letters 20 , 242-244.

IсHо, T. \& IINO, T. (1978). Isolation and characterization of motile Escherichia coli mutants resistant to bacteriophage $\chi$. Journal of Bacteriology 134, 854860.

King, C. A. \& Preston, T. M. (1977). Studies of anionic sites on the cell surface of the amoeba Naegleria gruberi using cationised ferritin. Journal of Cell Science 28, 133-149.

KORN, E. D. (1963). Fatty acids of Acanthamoeba sp. Journal of Biological Chemistry 238, 3584-3587.

KORN, E. D. \& WRIGHT, P. L. (1973). Macromolecular composition of an ameba plasma membrane. Journal of Biological Chemistry 248, 439-447.

OfeK, I., Mirelman, D. \& Sharon, N. (1977). Adherence of Escherichia coli to human mucosal cells mediated by mannose receptors. Nature, London 265, 623-625.

Preston, T. M. \& KInG, C. A. (1978). An experimental study of the interaction between the soil amoeba Naegleria gruberi and a glass substrate during amoeboid locomotion. Journal of Cell Science 34, 145-158. 
RAY, D. L. (1951). Agglutination of bacteria : a feeding mechanism in the soil amoeba Hartmanella sp. Journal of Experimental Zoology 118, 443-464.

Silverman, M. \& SimON, M. (1974). Flagellar rotation and the mechanism of bacterial motility. Nature, London 249, 73-74.

SMITH, D. G. (1982). Bacterial appendages. In Electron Microscopy of Proteins, vol. 2, pp. 105-151. Edited by J. R. Harris. London: Academic Press.

SteVEns, A. R., KilPatrick, T., Willaert, E. \& CAPRON, A. (1977). Serologic analyses of cell-surface antigens of Acanthamoeba spp. with plasma membrane antisera. Journal of Protozoology 24, 316-324.

TAYloR, R. B., Duffus, W. P. M., RAFF, M. C. \& DE PETRIS, S. (1971). Redistribution and pinocytosis of lymphocyte surface immunoglobulin molecules induced by anti-immunoglobulin antibody. Nature New Biology 233, 225-229.
Thompson, J. E. \& Pauls, K. P. (1980). Membranes of small amoebae. In Biochemistry and Physiology of Protozoa, vol. 3, pp. 207-253. Edited by M. Levandowsky \& S. M. Hutner. New York: Academic Press.

Visvesvara, G., Jones, D. \& Robinson, N. (1975). Isolation, identification and biological characterization of Acanthamoeba polyphaga from a human eye. American Journal of Tropical Medicine and Hygiene 24, 784-790.

Weisman, R. A. \& Korn, E. D. (1967). Phagocytosis of latex beads by Acanthamoeba. I. Biochemical properties. Biochemistry 6, 485-497.

Wright, S. J. L., Redhead, K. \& Maudsley, H. (1981). Acanthamoeba castellanii, a predator of cyanobacteria. Journal of General Microbiology 125 , 293-300 